\title{
UTILIZATION OF DIFFERENT TYPES OF FIBRES CEMENTOUS MATERIALS AND SBR LATEX IN THE CONCRETE - A REVIEW
}

\author{
B. Kanna Babu ${ }^{1}$, Bimalendu Dash ${ }^{2}$ \\ ${ }^{I} P G$ Student, Transportation Engineering, GMR Institute of Technology-Rajam \\ ${ }^{2}$ Assistant Professor, Dept. Of Civil Engineering, GMR Institute of Technology-Rajam
}

Article DOI: https://doi.org/10.36713/epra8410

DOI No: 10.36713/epra8410

\begin{abstract}
Concrete's tensile strength is low compared to its compressive strength when subjected to normal stresses and impact loads, making it brittle. Continuous reinforcing improves the strength and ductility of concrete, but it requires careful placement and the availability of labour. In this work, the impact of several types of concrete fibre characteristics was studied. The concept of using fibres to alter the characteristics of building materials isn't new. When concrete cracks and randomly oriented fibres start to operate together, they prevent crack development and extension while also increasing strength and ductility. The current trend is to develop more effective crack-resistant concrete, such as reinforced fibre concrete. The geometric size and modulus of fibres are the key factors of the mechanical performance of fibre reinforced concrete. According to the findings, adding fibres to concrete enhances compressive strength, flexural strength, split tensile strength, ductility, and impact strength.
\end{abstract}

KEY WORDS: Nylon Fibre; Latex; Compressive Strength; Split Tensile Strength; Flexural Strength, Durability.

\section{INTRODUCTION}

Along with its high compressive strength, concrete has become one of the most extensively utilised construction materials in the world today. Highperformance or high-strength concrete works substantially better than conventional concrete in terms of overall performance. In the case of highperformance or high-strength concrete, this is especially true. Concrete's brittleness is one of its most severe disadvantages. As concrete's strength grows, it becomes more brittle, which has a negative impact on its overall performance. Plain concrete is a brittle substance with a low modulus of rapture, as well as a low strain capacity and elasticity of rapture. Several research have been done in order to improve the properties of concrete, such as durability, ductility, flexural strength, fracture toughness, and load bearing capacity, in order to overcome this issue. One technique for overcoming these challenges is to use fibres in concrete.
Fibres are frequently used in concrete to prevent breaking caused by plastic shrinkage and shrinkage during the curing process. The insertion of discrete and long discontinuous fibres to conventional concrete to improve the concrete's cracking behaviour. Compressive strength, flexural strength, split tensile strength, ductility, and impact strength all improve when fibres are added. A variety of methods may be used to improve FRC blending operations. The fibres in the mix should be evenly dispersed throughout the mixture to prevent segregation. Fibre reinforced concrete has a lower coarse aggregate content, a higher fine aggregate content, and a higher cement content.

\section{DIFFERENT TYPES OF FIBERS USED IN THE CONCRETE}

Fibre Reinforced Composites Concrete is a composite material made up of cement, mortar, or concrete mixtures, as well as fibres that are 


\section{EPRA International Journal of Research and Development (IJRD)

discontinuous, discrete, and uniformly distributed. fibre reinforced concrete comes in a wide range of kinds and characteristics, each with its own set of advantages. fibre is a small piece of reinforcing material with specific qualities and features that may be used to reinforce a variety of materials. They come in a variety of shapes, including round and flat. A helpful parameter termed "aspect ratio" is frequently used to define the fibre. An aspect ratio of a fibre is defined as the ratio of its length to its diameter. The most common aspect ratio is between 30 and 150. fibre-reinforced concrete (FRC) is a form of concrete that incorporates fibrous material that reinforces the concrete and improves its structural integrity. Fibres are widely used in concrete to reduce shrinkage cracking caused by both plastic and drying shrinkage. They also have the effect of decreasing the permeability of concrete and, as a result, reducing water bleeding. When utilised in concrete, several types of fibres offer better impact, abrasion, and shatter resistance than regular concrete. Variations in the properties of the mix may be seen by varying the distribution, shape, and orientation of fibres in fibre reinforced concrete. Fibre reinforced concrete is made up of a variety of various fibre kinds.

- Steel fibres

- Glass fibres

- Polypropylene fibers

- Carbon fibers

- Basalt fibers

- Polyester fibers

- Asbestos (mineral) fibers

- Cellulose fibers

- Nylon fibers

- Coconut fibers

- Cotton fibers

- Bamboo fibres

This paper focuses on the researches that had done on the concrete by using different SBR latex with different materials

\section{LITERATURE REVIEW}

Kim Hung Mo et al (2014) has found that introducing has a splitting tensile strength in the range of 2.3-3.5 $\mathrm{MPa}$, with a decrease in strength when the GGBS concentration is increased. Standard NWC had a significantly reduced ratio of split tensile to compressive strength than GGBS-based OPSC, which was discovered to be a minor difference. As the amount of OPC replaced with GGBS increased, the flexural strength decreased in a similar manner as the splitting tensile strength. In contrast, the flexural to compressive strength ratio of GGBS-based OPSC was comparable to that of conventional NWC. The chloride ion penetration was reduced when one particle of blast furnace slag was added, suggesting that the water permeability resistance had been improved. As the fibre volume fraction rose, the amount of chloride ions that could be absorbed decreased. Steel fibre has been shown to have a lower resistance to water permeability than macro synthetic fibre.

Yacine Benali et al (2016): has found that increasing the quantity of latex (SBR and SA) used to substitute cement in the cementitious mix reduces the amount of mixing water needed in the cementitious mix. As a result, latex may be used as a water-saving agent in a variety of applications. The compressive strength of a concrete mix increases as the quantity of cement in the mix increases as well as as time passes. However, increasing the amount of polymer in the mix (beyond $10 \%$ by weight cement replacement) leads in a loss in open porosity accessible to water as well as a decrease in the mix's compressive strength. It also results in a longer-lasting improvement in flexural tensile strength of more than 60 days. It was also observed that after 28 days, the drying of changed mortars had a significant impact on the flexural tensile strength of the mortar. Another advantage of SBR- and SA-modified mortars is increased binding strength between mortars and clay bricks, as well as between mortars and cement substrates. Failure occurs exclusively inside clay substrates in modified mortars having more than $10 \%$ cement replacement, as opposed to low substitution levels, when failure occurs at the interface between clay and other construction components. On the other hand, failure always occurs at the interface on flat cementitious substrates, regardless of the formulation employed.

Woong Kim et al (2017): had found that the impact of different reinforcing fibre types and micro silica on the performance of LMFRCRSC for a concrete pavement emergency repair was investigated in this study. After 4 hours of curing, the compressive and flexural strength tests revealed that the strength of the material declined when the micro silica replacement ratio was raised. Up to a micro silica substitution ratio of 2 percent, a target compressive strength of 21 $\mathrm{MPa}$ and a target flexural strength of $3.5 \mathrm{MPa}$ were obtained for the jute fibre reinforced concrete mix after four hours of curing in a controlled environment. As long as the micro silica replacement ratio did not exceed 3 percent when the macro synthetic fibre was combined, the 4-hour curing goal strength could be achieved. In proportion to the rise in substitution ratio, the chloride ion penetration decreased. After curing for 28 days, all of the mixes achieved the desired chloride ion penetration of 2000 degrees Celsius. In terms of the reinforcing fibre, chloride ion penetration was reduced more with macro synthetic fibres than with jute fibres, although the difference was only marginally significant. When it comes to abrasion resistance, the higher the micro 


\section{EPRA International Journal of Research and Development (IJRD)

silica substitution ratio, the better the abrasion resistance characteristics. Regarding fibre type, macro synthetic fibres outperformed jute fibres by a little margin

Gorle et al (2018): The impact of Nylon fibre and SBR latex on the quality and strength of cement for the M40 grade has been studied. Fibre was utilised in amounts of 0.05 percent, 0.1 percent, and 0.15 percent of total cement volume, respectively. The amounts of SBR latex utilised were $5 \%, 10 \%$, and $15 \%$ of the total volume of cement, respectively. The highest level of quality was reached using a 0.1 percent nylon fibre and 10\% SBR latex combination, according to the data.

Manikandan et al (2017): An experimental study of nylon fibre reinforced concrete with a strength grade of M25 is provided in this publication. Fine aggregate is substituted with nylon fibre at percentages of $2 \%, 4 \%$, and $6 \%$, depending on the findings, in this study. The flexural strength of specimens cast with $2 \%$ nylon fibre was found to be higher than that of specimens cast with $4 \%$ and $6 \%$ nylon fibre. The compressive strength of specimens cast with $4 \%$ nylon fibre was found to be higher than specimens cast with $2 \%$ and $6 \%$ nylon fibre, respectively. Specimens cast with 6 percent nylon fibre had a greater split tensile strength than those cast with 2 percent and 4 percent nylon fibre, respectively. In general, when compared to regular concrete, nylon fibre reinforced concrete outperformed ordinary concrete in the majority of the cases.

Bhat et al (2018): The researchers measured the split tensile and compressive strength of normal concrete (NC), steel fibre reinforced concrete (SFRC), polymer modified concrete (PMC), and polymer modified steel fibre reinforced concrete (PMSFRC), as well as the percentage increase in strength achieved by adding steel fibres and silicone rubber. After 28 days of curing, compressive strength increases by 31.98 percent, 16.93 percent, and 36.16 percent, respectively, while tensile strength increases by 38.85 percent, 21.65 percent, and 47.72 percent when SFRC, PMC, and PMSFRC are compared to ordinary concrete cubes. In the PMSRF test specimens, compressive and tensile strengths were obtained with $3 \%$ steel fibre addition and 15\% SBR replacement with cement.

Saxena et al (2015): According to the research authors, adding nylon fibre in varied amounts to conventional concrete enhanced the concrete's strength. Fly ash was utilised to replace 0.2 percent, 0.25 percent, and 0.3 percent of the volume of concrete and cement with percentages of (10 percent,
$20 \%$, and $30 \%$ ) fly ash, respectively. The tests are carried out after seven, fourteen, and twenty-eight days. The addition of $10 \%$ fly ash to the cement, as well as $0.2,0.25$, and 0.3 percent nylon fibre, increases the performance of conventional concrete, according to research.

Akaram et al (2018) The addition of various quantities of nylon fibre to concrete, ranging from 0.5 percent to 1.5 percent by weight, has been discovered to improve the mechanical properties of the concrete. In a ten percent replacement for cement, metakaolin was utilised. This study doesn't include the separate work for metakaolin and nylon fibre combined and mixed in concrete, as has been done in previous studies.

Sujatha (2016) The research examined at the durability of waste admixed high strength concrete, as well as how the mechanical characteristics of M30 grade concrete were impacted when metakaolin and GGBS were used as partial replacements for cement and copper slag was used as a partial replacement for fine aggregate. The research of the strengthen characteristics of M30 grade concrete included sorpitivity, porosity, acid attack, and water absorption tests in order to identify the optimal \% value for which the concrete displays better strength.

Radhakrishnan et al (March 2017) Presents the results of an experimental research into the strength characteristics of latex-modified jute fibre reinforced concrete. Specifically, two types of jute fibres were employed in this study, namely raw jute and modified jute, and their strength qualities were evaluated in comparison. The proportion of fibres is expressed as a percentage of the total weight of the cement. Comparing the findings of the tests with those of raw jute fibre, it was discovered that the modified jute fibre had higher compressive and split tensile strengths.

Sachin Kumar et al (May 2017) has examined at the strength properties of steel fibre reinforced concrete that has been modified using polymeric reinforcement. According to the findings, the polymer utilised in this investigation was acrylic latex, and the concrete grade used was M25. The compressive strength of M25 grade concrete is examined in this study using a range of steel fibre and acrylic latex combinations. Compressive strength is reduced when acrylic latex is used, while tensile and flexural strength are increased when steel fibre is used. This increase in compressive strength is due to the compactness of concrete. 


\section{EPRA International Journal of Research and Development (IJRD)}

Sumathi et al (2015) It describes a research project on the mechanical characteristics of steel fibre reinforced concrete. M40 is the design mix that has been selected for this investigation. The fibres were added to the concrete at concentrations of 0.5 percent, 1 percent, 1.5 percent, and 2 percent by volume of concrete, respectively. Using fibres as reinforcement in concrete, researchers discovered that the compressive strength, split tensile strength, and modulus of rupture values increased at 28 days when compared to standard concrete. At a fibre level of 1.5 percent, the mix has a higher sorption coefficient, which is more important for durability.

Y Chandrasekhara Varma et al (May 2017) investigates the mechanical characteristics of hybrid fibre reinforced concrete with polymer modifications. The characteristics of M30 grade conventional concrete, mono steel fibre concrete, and polymer modified hybrid fibre concrete were investigated in this study, and the properties of polymer modified hybrid fibre concrete were compared to those of conventional and mono steel fibre concrete. The results reveal that polymer modified hybrid fibre concrete has a 41 percent increase in flexural strength, a 45 percent increase in split tensile strength, and a 25 percent increase in compressive strength when compared to traditional concrete. When compared to ordinary concrete and mono steel fibre concrete, a mixture of 0.2 percent polyester fibre and 0.5 percent steel fibre produces superior outcomes.

T. N. Janbandhu et al (April 2017) provides research into fibre reinforced concrete with a modified polymer in an experimental setting. Basalt fibres were utilised in this experiment. The acrylic polymer used in this study is $10 \%$ by weight of the cement, and the basalt fibre concentration ranges from $1 \%$ to $5 \%$ by weight of the cement. The findings demonstrate that the workability of polymer modified fibre reinforced concrete diminishes as the fibre percentage increases. In contrast to normal concrete, the compressive strength, split tensile strength, and shear strength improved with a fibre content of $4 \%$.

S.S. Kadam et al (May 2017) The mechanical characteristics of high-strength steel fibre reinforced concrete at various aspect ratios are investigated (65 and 80 ). Steel fibre is changed at a 0.5 percent by volume interval in this investigation. Experiments demonstrate that as fibre volume rises, flexural strength increases, with maximum flexural strength being seen at an aspect ratio of 80 .

Akshara S et al (May 2017) focuses on the mechanical characteristics of modified latex fibre reinforced concrete. In this experiment, polypropylene fibre and SBR latex were utilised. The results demonstrate that the compressive strength falls when latex and fibre are added. With the addition of fibre and latex, flexural strength, split tensile strength, and abrasion resistance all improve. When latex and fibre are added together, the flexural strength is enhanced more than when they are added separately. At a fibre concentration of 0.3 percent and a latex content of $15 \%$, the abrasion resistance and impact resistance are at their peak.

Kothai.P et al (April 2017) focuses on the characteristics of fibre reinforced concrete. During this study, fine aggregate is replaced with marine sand and mix is designed for M60 grade concrete. The fibres were added at a dosage of $0 \%, 0.5 \%, 1 \%$, $1.5 \%$ and $2 \%$ by weight of the cement. The results show that there is an increment in compressive strength about $5.5 \%$ at fibre content of $1 \%$ and with sea sand. From the experimental tests it can be observed that at 28 days the compressive strength, split tensile strength and flexural strength are found to be $64.05 \mathrm{MPa}, \quad 5.72 \mathrm{MPa}$ and $6.515 \mathrm{MPa}$ respectively

\section{CONCLUSION}

In compression, concrete is strong, however in tension, it is weak. Fibers added to concrete will increase its tensile strength. When compared to ordinary concrete, the mechanical characteristics of FRC were shown to be superior. Adding fibres to the concrete mix alone increases toughness, ductility, and tensile characteristics, according to several experimental investigations, but increases in toughness, ductility, and tensile qualities does not enhance toughness, ductility, or tensile values. When GGBS is added to concrete, its workability improves, but it has an influence on the concrete's setting time. There is a reduction in compressive strength when SBR latex is used alone in concrete. The combination of GGBS, SBR latex, and fibres has been shown to improve the mechanical characteristics of concrete in numerous experimental investigations.

\section{REFERENCES}

1. Benali, Y., \& Ghomari, F. (2017). Latex influence on the mechanical behavior and durability of cementitious materials. Journal of adhesion science and Technology, 31(3), 219241.

2. Kim, W., Jeon, J. C., An, B. H., Lee, J. H., Kim, H. D., \& Park, C. G. (2018). Effects of reinforcing fiber and microsilica on the mechanical and chloride ion penetration properties of latex-modified fiber-reinforced rapid-set cement concrete for pavement repair. Advances in Materials Science and Engineering, 2018. 


\section{EPRA International Journal of Research and Development (IJRD)

3. Mo, K. H., Alengaram, U. J., \& Jumaat, M. Z. (2015). Utilization of ground granulated blast furnace slag as partial cement replacement in lightweight oil palm shell concrete. Materials and structures, 48(8), 2545-2556. K Manikandan, A Arun Kumar "Experimental investigation on nylon fiber reinforced concrete". International Research Journal of Engineering and Technology (IRJET) Volume: 04 PP. 24792482, 2017.

4. Jaya Saxena, Prof. Anil Saxena "Enhancement the strength of conventional concrete by using nylon fibre". International Journal of Engineering and Science Volume: 5, PP. 56-59, 2015.

5. S Sujitha, N Sakthieswaran "Durability strength waste admixed high strength concrete". International Journal for Research in Applied Science \& Engineering Technology (IJRASET) Volume: 4, PP. 658-662, 2016.

6. Akaram Ali, Aleem Aijaz "A study on nylon fibre reinforced concrete by partial replacement of cement with metakaolin: a literature review". International Research Journal of Engineering and Technology (IRJET) Volume: 05 PP. 23672369, 2018.

7. Bimalendu Dash, Gorle Lokeswararao "Strength and durability performance of latex modified fiber reinforced concrete". International Journal of Civil Engineering and Technology (IJCIET) Volume: 9, PP. 477-486, 2018.

8. D.Radhakrishnan et al (March 2017). "Strengthening of Concrete Using Jute with Polymer". International Journal of Innovative Research in Science, Engineering and Technology Volume 06 Issue 03.

9. Sachin Kumar et al (May 2017)." Strength Behaviour of Concrete Using Polymer Modified and Steel Fiber Reinforced Concrete". International Research Journal of Engineering and Technology Volume 04 Issue 05.

10. Y Chandrasekhara Varma et al (May 2017). "Sbr Latex Based Hybrid Fiber Reinforced Concrete". International Journal of Civil Engineering (SSRG-IJCE)- Volume 4 Issue 5.

11. T. N. Janbandhu et al (April 2017). "An Experimental Investigation on Basalt Fibre Reinforced Concrete with Acrylic Polymer ". International Journal of Science and Research Volume 06 Issue 04.

12. S.S. Kadam and V.V. Karjinni (May 2017). "Effect of different aspect ratio of steel fiber on mechanical properties of high strength concrete". The Indian Concrete Journal.

13. Akshara S and Shibi Varghese (May 2017). "A Study on Properties of SBR Latex Modified Polypropylene Fibre Reinforced Concrete". International Journal of Science Technology \& Engineering Volume 3 Issue 11.

14. Kothai.P and Lakshmi narayanan. $S$. "Mechanical Properties of Fiber Reinforced High Performance Cocrete Using Marine Sand IS 2386: Methods for testing of aggregates for concrete.
15. Athira Omanakuttan and Aruna C (February 2017). "An Experimental Study On Strength Behaviour of Steel Fiber, Glass Fiber with Fly Ash and Rice Husk Ash". International Journal of Engineering Science and Computing Volume 7 Issue 2.

16. Tehmina Ayub et al (October 2014)." Effect of Chopped Basalt Fibers on the MechanicalProperties and Microstructure of High Performance Fiber Reinforced Concrete". Advances in Materials Science and Engineering.

17. U.B.Kalwane et al (February 2016). "Toughness of Polymer Modified Steel Fiber Reinforced Concrete". Open Journal of Civil Engineering.

18. Aiswarya Sukumar and Elson John (September 2014)." FIBER ADDITION AND ITS EFFECT ON CONCRETE STRENGTH". International Journal of Innovative Research in Advanced Engineering Volume 1 Issue 8.

19. Pooja Shrivastava and Dr.Y.p. Joshi (December 2014). "Reuse of Lathe Waste Steel Scrap in Concrete Pavements". International Journal of Engineering Research and Applications Volume 04 Issue 12 (Part 4).

20. Deepa K Venu and Prof. M. Rajalingam (April 2016). "Study On the Mechanical Properties of Concrete Using Scba and Coir Fibres". International Journal of Innovative Science, Engineering \& Technology, Vol. 3 Issue 4. 